\title{
THE ROLE OF ECONOMIC ANALYSIS IN POLICY MAKING -A TOBACCO CONTROL CASE STUDY
}

\section{Anita Tang and Andrew Penman \\ The Cancer Council New South Wales}

Economic analyses and modelling can influence the development of public health policy by providing evidence about the economic impact of different policies and the return on investment for policy changes, as well as any differential outcomes arising from policy implementation. Such analyses can also provide data relevant to broader factors that impact on policy decisions.

This article describes the use of an economic analysis of a reduction in smoking prevalence to counter competing claims of industry interest groups, and to identify the potential beneficiaries of tighter tobacco control policies.

\section{BACKGROUND}

\section{Tobacco control-a case study in public policy} impasse

Tobacco use is the largest single preventable contributor to premature death and chronic illness in Australia. Tobacco use imposes substantial, yet avoidable, costs on smokers and their families, as well as on the community generally, through costs to the health system and to business.

Although Australia leads the way in many areas of tobacco control, the situation remains well short of optimum. There are a number of notable policy opportunities that would substantially reduce smoking rates, including funding of a comprehensive anti-tobacco social marketing campaign, legislating for smoke-free pubs and clubs, and tighter regulation of the tobacco retail distribution environment. There is ample evidence that social marketing campaigns can rapidly accelerate the decline in the prevalence of smoking, and numerous evaluations demonstrating substantial economic and health benefits from such campaigns. ${ }^{1-4}$ Despite the evidence, it has become increasingly difficult to engage policy makers of all levels and persuasions about the need for tighter tobacco control policies.

\section{Barriers to policy decisions in favour of tighter tobacco control}

There are many reasons why policy makers may be reluctant to pursue tighter tobacco control policies. These include the perception that the 'smoking problem' has been sufficiently addressed and that everyone is already aware of the health impact of smoking, resulting in an attitude of policy complacency or weariness in relation to tobacco control policy. The long timeframe on returns on investment in tobacco control also reduces the likelihood of governments seeing this as an urgent or high pay-off policy issue.

Reasons could also include those relating to a balance of power and visibility of different stakeholders involved in tobacco. There is a limited visible constituency pushing for tighter tobacco control measures, in contrast to the visibility and power of the constituency with vested economic interests in tobacco use. This is exemplified by the aggressive campaigns by pubs and clubs over controls on environmental tobacco smoke, and by the newly formed National Alliance of Tobacco Retailers, established with tobacco and energy company support, to oppose further point of sale controls. The pro-tobacco interests have relied increasingly on economic arguments to counter any attempts at tighter tobacco control, by asserting that reduced smoking rates would have detrimental effects on the economy overall.

In contrast, government as a whole is yet to engage with the impact of tobacco and the challenge of tobacco control. Policy makers generally take the view that tobacco control is exclusively a health issue and therefore all initiatives should be funded from within existing health budgets. Senior politicians often express views that mirror the tobacco industry position - that tobacco is a legal product and the decision to smoke is a personal adult one-and state this as a reason for resisting a tighter tobacco control policy.

The Cancer Council New South Wales commissioned an economic analysis of the effects of reduced smoking prevalence in NSW to provide empirical evidence about the impact of tighter tobacco control policies. This analysis provides an opportunity to reframe the tobacco control issue in terms of economic, not just health, outcomes.

The full report describing the study by Juror, Collins and Lapsley, The macroeconomic and distributional effects of reduced smoking prevalence in New South Wales, has been published by the Cancer Council New South Wales. Here we summarise the purpose of the study, the method, and major findings.

\section{METHODS}

The economic analysis was designed to contribute to policy making in three main ways:

- by quantifying the extent and direction of any economic effect of reduced smoking prevalence

- by assessing the validity or otherwise of the claims made by tobacco industry interests about the economic harm from reducing smoking prevalence

- by identifying potential economic beneficiaries of tighter tobacco control policies with a view to developing a broader constituency in support of such policies.

The economic analysis examined the impact on output, employment and other economic variables in NSW 
resulting from a reduction in smoking prevalence in NSW of one percentage point per year over a five-year and tenyear period.

The analysis took into account alternative expenditure patterns at a household level resulting from (a) a reduction in expenditure on smoking and (b) a range of possible government budgetary response to changes in tobacco tax revenue resulting from reduced consumption. The economic analysis was based on modelling the effects of four different scenarios with various plausible combinations of budgetary responses.

This allowed the analysis to identify which business sectors would be advantaged or disadvantaged by lower smoking prevalence. It also provided data on the effects of reduced smoking prevalence on:

- distribution of household income

- federal and state government budgets

- sectoral employment

- balance of payments

- NSW gross state product.

\section{RESULTS}

The results described here are reported in Junor, Collins and Lapsley, The macroeconomic and distributional effects of reduced smoking prevalence in NSW.

\section{Empirical evidence about the direction and extent of economic impact}

The analysis concluded that the effects of a 25 per cent decline in NSW smoking rates upon aggregate NSW output and employment would be minor, and that the direction of the effect would depend on which budgetary response was adopted by the government. The analysis identified a number of NSW industries that would experience increased outputs and employment as a result of reduced smoking prevalence, as well as those that might experience a downturn. However, any reductions in output or employment in specific industries would be easily absorbed by the effects of overall economic growth in the economy over the five-year period.

\section{Countering tobacco industry arguments}

The tobacco industry has commissioned various reports purporting to demonstrate that it makes a major contribution to national economic output and employment. However, many of these studies failed to take into account that any reduction in spending on tobacco will inevitably be accompanied by an increase in either spending on other goods and services or on savings. The economic analysis conducted by Junor, Collins and Lapsley assumed that households that quit smoking would spend the money freed in the same way as non-smoking households.

The economic analysis in all scenarios tested clearly refutes tobacco industry claims about the economic harms that would result from reduced smoking prevalence. The analysis showed that the only significant loser would be the tobacco industry.

The evidence from this economic analysis should enable policy makers to dismiss the claims of the tobacco industry that there would be large negative effects on the economy from reduced smoking prevalence. The fact that the economic impacts of reduced smoking prevalence would be close to neutral means that they should not be an obstacle to framing a policy response to the continued problem of tobacco use in the community.

\section{Constituency building}

One of our objectives in commissioning the economic analysis was to identify any particular sectors that would gain from reduced smoking prevalence in order to build a more visible constituency for tighter tobacco control policies. This would help change the current imbalance in constituency power between the tobacco industry and its allies, and those calling for improved tobacco control. A broader recognisable constituency for tobacco control would also assist in increasing the relevance of tobacco control to government portfolios beyond health.

The economic analysis did not identify any industry sector that would particularly benefit from a reduction in smoking prevalence, given that the overall effects were found to be close to neutral.

However, the analysis of the impact of reduced smoking prevalence on household expenditure showed that, relative to income, the greatest benefits of additional income freed up through reduced smoking would accrue to the poorest households in NSW. The research estimated that the poorest households could achieve average savings of over \$14 per week at the end of five years where smoking prevalence was reduced by one percentage point per year, and savings of almost \$29 per week at the end of ten years under the same assumptions. Importantly, these figures represent the average for all households, including those where smoking continues. The impact on the lowest income households that quit would be much greater as these households spend an average of 18 per cent of household income on tobacco.

These results highlight the fact that tobacco control provides a tangible opportunity for reducing the impact of poverty, and so should be of relevance to the social services sector and those government agencies concerned with poverty alleviation. The data clearly demonstrated that a reduction in smoking prevalence across the community would provide the greatest financial benefit to the poorest households in the state.

\section{DISCUSSION}

The reality of public policy making and influence is that the process is not a direct linear one from evidence to policy. There are many factors that impact on decisions of policy makers, and empirical evidence is only one of these. The challenge is to ensure that research is designed in a way that 
addresses the broader factors that impact on policy decision making such as competing policy and economic interests and the political context, and that takes into account the mechanisms and structures of public policy making. ${ }^{6}$

The research described in this article was explicitly designed to address some of the broader factors impacting on decision-making in relation to tobacco control policy. These included the need to address the claims of the tobacco industry interests that tobacco control would have a detrimental impact on the economy; to provide information to policy makers on the economic (rather than health) impact of tobacco control policies; and to identify the economic beneficiaries of tighter tobacco control policies.

One of the most important outcomes of this research was the evidence that the poorest households would have the most to gain from a reduction in overall smoking prevalence in NSW through tighter tobacco control policies. This provided an opportunity to demonstrate the relevance of tobacco control to the social services sector, and to policy makers concerned with reducing the impact of poverty.

Copies of The macroeconomic and distributional effects of reduced smoking prevalence in New South Wales can be obtained from Sarah Ford at the Cancer Council New South Wales by contacting her on 0293341753 or sarah@ @swcc.org.au.

\section{REFERENCES}

1. California Department of Health and Human Services. Just say no. Economist 12 Sept 2000; 357(8200): 36.

2. Cancer Strategies Group. Priorities for action in cancer control, 2001-2003. Canberra: Commonwealth of Australia, 2001

3. Hassard K (editor). Australia's national tobacco control campaign: Evaluation report. Vol 2. Canberra: Commonwealth of Australia, 2000.

4. Collins DJ, Lapsley HM. The social costs of tobacco in Western Australia and the social benefits of reducing Western Australian smoking prevalence. West Perth: Cancer Foundation of WA, 2001.

5. Junor W, Collins D, Lapsley H. The macroeconomic and distributional effects of reduced smoking prevalence in New South Wales. Sydney: The Cancer Council New South Wales, June 2004.

6. Petticrew M, Whitehead M, Macintyre SJ, Graham H, Egan M. Evidence for public health policy on inequalities. (1) The reality according to policy makers. J. Epidemiol. Community Health 2004; 58: 811-16. 용 